
Henry Robben*

\title{
Engaging Through Purpose: The Mediating Role of Person- Organizational Purpose Fit in the Relationship Between Perceived Organizational Purpose and Work Engagement ${ }^{* *}$
}

\begin{abstract}
Drawing from self-determination theory and person-organization fit theory, the present study contributes to the literature on organizational purpose by examining the relationship between perceived organizational purpose and work engagement and the mediating role of person-organizational purpose (P-OP) fit herein. Based on data from a cross-sectional quantitative study among 517 knowledge workers from five financial service organizations, we tested two possible psychological mechanisms underlying the direct and indirect relationships between perceived organizational purpose and work engagement. The results of our structural equation modelling confirmed the hypothesized indirect effect model in which perceived organizational purpose was positively associated with work engagement, both directly and indirectly via P-OP fit. These findings show that organizational purpose has the capacity to directly and indirectly foster work engagement. The study suggests avenues for future research in OB, strategic HRM, and marketing.
\end{abstract}

Keywords: Perceived organizational purpose; work engagement; self-determination theory; P-O fit theory

(JEL: J24, J290, M14, M54)

\section{Introduction}

Since the 2007 financial and economic crisis, organizational misconduct has led to an increased level of distrust and disengagement among stakeholders (Hollensbe, Wookey, Loughlin, George, \& Nichols, 2014; Wang, Tong, Takeuchi, \& George,

* Ramon van Ingen (corresponding author): Nyenrode Business University, Center for Strategy, Organization and Leadership, Breukelen, Netherlands. E-Mail: ramonvaningen@icloud.com

Dr. Melanie De Ruiter: Nyenrode Business University, Center for Strategy, Organization and Leadership, Breukelen, Netherlands. E-Mail: M.dRuiter@nyenrode.nl

Prof. Dr. Pascale Peters: Nyenrode Business University, Center for Strategy, Organization and Leadership, Breukelen, Netherlands. E-Mail: P.Peters@nyenrode.nl

Prof. Dr. Bas Kodden: Nyenrode Business University, Center for Strategy, Organization and Leadership, Breukelen, Netherlands. E-Mail: B.Kodden@nyenrode.nl

Prof. Dr. Henry Robben: Nyenrode Business University, Center for Marketing and Supply Chain Management, Breukelen, Netherlands. E-Mail: H.Robben@nyenrode.nl

** Date submitted: November 4, 2019.

Date accepted after double blind review: August 10, 2020. 
2016). As a result, the organization's relationship and enduring connection with stakeholders, including employees, have been undermined (Ehnert, 2014; Hollensbe et al., 2014). The importance of organizational purpose has been increasingly stressed by both the scholarly (e.g. Hollensbe et al., 2014) and professional management literatures (e.g. Montgomery, 2019) as organizational purpose acknowledges the interdependence of organizations, business and society and focuses on the well-being of society and its constituents (e.g. Hollensbe et al., 2014). Therefore, organizational purpose is expected to be capable of building and fostering trust, reinforcing relationships, and through its motivational force is likely to have the potential to inspire and foster action amongst stakeholders (Ehnert, 2014; Hollensbe et al., 2014; Hurth, Ebert, \& Prabhu, 2018; Montgomery, 2019). The present study defines organizational purpose as "an aspirational reason for being which inspires and provides a call to action for an organization and its partners and stakeholders and provides benefit to local and global society" (Harvard Business Review [HBR], 2015, p. 1).

The anticipated benefits of intentionally articulating a clear organizational purpose for organizations and their stakeholders are said to be multiple (e.g. Montgomery, 2019). These benefits may include benefits that are needed to guarantee the organization's continuity (Williams, 2019), such as improved financial performance and increased shareholder value (HBR, 2015). In addition, in view of the war on highly skilled and motivated employees, a clearly articulated organizational purpose may lead to attractiveness, retention and work engagement of employees that fit the organization (Collins \& Porras, 2008; Dimiziani, 2019; Hurth et al., 2018; Williams, 2019) as organizations anticipate that the articulated organizational purpose resonates with employees' values, interests and might satisfy needs for purpose and meaningfulness which in turn might lead to personal well-being (App, Merk, \& Büttgen, 2012; Ehnert, 2014; Hurth et al., 2018; Lysova, Allan, Dik, Duffy, \& Steger, 2019; Rosso, Dekas, \& Wrzeniewski, 2010). These latter potential outcomes suggest that organizational purpose can serve as an important element in strategic human resource management (SHRM) in achieving competitive advantage through employer branding (App et al., 2012; Ehnert, 2014) and fostering employee work engagement through organizational purpose's motivational force (Collins \& Porras, 2008; Dimiziani, 2019; Hurth et al., 2018; Moynihan \& Pandey, 2007). In fact, disengagement amongst employees in work environments is a serious problem for organizations (Rastogi, Pati, Krishnan, \& Krishnan, 2018). Empirical research on work engagement, which is defined as "a positive work-related state of fulfilment that is characterized by dedication, vigor, and absorption" (Schaufeli, Salanova, Gonzalez-Roma, \& Bakker, 2002, p. 74), suggests a positive relationship between work engagement and organizational performance via enhanced in-role and extra-role performance (e.g. Bakker, Demerouti, \& Sanz-Vergel, 2014). However, whether the articulated organizational purpose fosters the intended psychological processes at the individual level much depends on how these are perceived by 
the employees as intended organizational practices do not necessarily align with employee perceptions (e.g. Nishii \& Wright, 2007; Piening, Baluch, \& Ridder, 2014; Sanders \& Yang, 2016). Hence, only when employees perceive that the organization's purpose fits their values, interests and needs, they will be motivated to act in line with the organizational goals leading to performance (e.g. Piening et al., 2014; Sanders \& Yang, 2016).

In view of the account above, the present study focuses on the motivational potential of employee perceived organizational purpose as this may directly and indirectly influence employees' work engagement (Dimiziani, 2019; Hurth et al., 2018; Palmer, Quinn Griffin, Reed, \& Fitzpatrick, 2010) by fostering perceived person-organizational purpose fit (P-OP fit) which can be regarded as a type of value congruence between an individual and the organization (Dimiziani, 2019; Ellsworth, 2002). Despite the suggested potential motivational role of organizational purpose as perceived by employees in engaging them in their work, up until now there is only little scholarly knowledge on the relationship between perceived organizational purpose and work engagement and the underlying mechanisms affecting this relationship. This relationship can be explained by motivation theory, specifically self-determination theory (SDT; Deci \& Ryan, 2000), since organizational purpose may satisfy basic psychological needs (i.e. autonomy, relatedness and competence) and promote motivation through which personal well-being and, collectively, societal well-being can be strived for (Collins \& Porras, 2008; Hurth et al., 2018; Ryan \& Deci, 2019, in press).

Our research contributes to the literature on organizational purpose in several ways. First, we contribute to the literature on organizational purpose by examining the extent to which employee perceived organizational purpose is directly related to work engagement. Little if any research has been done on organizational purpose, and to the best of our knowledge, organizational purpose as perceived by employees has not yet been researched in relation to employees' work engagement. In the present study, we draw on SDT (Deci \& Ryan, 2000) to argue that organizational purpose as perceived by employees can have motivational potential and can foster work engagement directly at the employee level (Hurth et al., 2018; Palmer et al., 2010). Hence, perceived organizational purpose might be an antecedent of work engagement (e.g. Bakker et al., 2014).

Second, building on SDT as the overarching theory, we incorporate P-O fit theory (Kristof, 1996) to examine an underlying mechanism between employee perceived organizational purpose and work engagement that may explain the motivational potential that perceived organizational purpose might have at the individual level through fostering perceived P-OP fit (Dimiziani, 2019; Ellsworth, 2002).

Third and finally, we offer practical implications for managing organizations on the value of perceived organizational purpose and how perceived organizational purpose supports the psychological need for satisfaction that brings out employees' work 
motivation and engagement leading to organizational performance (Bakker et al., 2014).

In the next sections, we conceptualize perceived organizational purpose, work engagement and P-OP fit, and we build on SDT (Deci \& Ryan, 2000) incorporating P-O fit theory (Kristof, 1996) to develop our hypotheses. After that, we explain how we conducted our quantitative study using structural equation modelling (SEM) among 517 knowledge workers from the Dutch financial services industry in order to test our conceptual model in which perceived organizational purpose is hypothesized to be positively associated with work engagement, both directly and indirectly via P-OP fit. Then we will present our results. We will conclude by discussing the findings considering our theory and the debate on purpose and work engagement and their implications for future research and HRM.

\section{Theory and Hypotheses}

\section{Employee Perceived Organizational Purpose}

In academic literature, organizational purpose has often been defined as the reason for which an organization is created and exists (e.g. Ellsworth, 2002; Springett, 2005). However, emerging conceptualizations of organizational purpose show that organizational purpose has been reconceptualized to focus not only on why an organization exists but to also consider the stakeholders who are affected, and how organizations enact and activate their purpose to fulfil human needs or solve societal problems - in other words, how to contribute to the well-being of society and its constituents (Hollensbe et al., 2014; Hurth et al., 2018; Montgomery, 2019; Moynihan \& Pandey, 2007). In the present study, we focus on perceived organizational purpose as the perceptions of the organization's purpose are critical to responses at the individual employee level (cf. Nishii \& Wright, 2007). It is suggested that when employees perceive an organization's purpose to be aspirational inspiring a call to action and being beneficial to multiple stakeholders, it is likely to fuel employees' levels of energy, drive action and foster employees' willingness to devote their energy to work volitionally (Collins \& Porras, 2008; Hurth et al., 2018). Moreover, such perceptions can create a sense of belonging and acknowledge the transcendence of organizational purpose and the interdependence of organizations, business and society. Furthermore, these perceptions can provide employees with the experience of having challenging positive impact by doing work they are good at, which benefits society (Collins \& Porras, 2008; Hurth et al., 2018).

Though related, organizational purpose differs from concepts such as mission, vision, and values. A mission determines what you do as an organization in terms of specific activities and goals and has a specific timeline for its achievement. The overarching purpose is by contrast less specific and enduring and links the activities and goals set forth in the mission (Collins \& Porras, 2008; Hurth et al., 2018). A vision is set by leadership and represents an imagined future state of what it will be 
like when the purpose is being lived and the mission accomplished. Organizational purpose thus fuels the organization's vision (Hurth et al., 2018). Organizational purpose differs from organizational values in that it is considered an outgrowth of core organizational values and therefore is value based (Collins \& Porras, 2008; Lips-Wiersma, 2002). Organizational purpose states why an organization exists, whereas values express what is important to an organization and purpose is propelled into existence through values that guide organizational behaviour (Dimiziani, 2019; Ferguson \& Milliman, 2008).

\section{Work Engagement}

Work engagement encompasses three dimensions - vigour, dedication and absorption (Schaufeli et al., 2002). Vigour, the physical component, is characterized by high levels of energy, the willingness to devote energy into work, and resilience (Schaufeli et al., 2002). Dedication is the emotional component of work engagement and refers to experiencing a sense of significance, inspiration, and challenge at work (Schaufeli et al., 2002). The cognitive component, absorption, is characterized by being fully immersed in work and the experience of the rapidly passing of time (Schaufeli et al., 2002).

\section{The Relationship between Perceived Organizational Purpose and Work Engagement}

In the present study, we draw from self-determination theory (SDT) (Deci \& Ryan, 2000) to explain the relationship between perceived organizational purpose and work engagement and its underlying mechanisms. SDT is a broad framework for comprehending aspects that foster or thwart people's motivation and psychological well-being (Deci \& Ryan, 2000). A core tenet of SDT is that people seek to thrive and grow psychologically to achieve well-being through the satisfaction of their basic psychological needs (Deci \& Ryan, 2000; Ryan \& Deci, 2019, in press). SDT distinguishes three basic psychological needs in human thriving and motivation. These are the need for autonomy (i.e. psychological freedom, acting of free will), the need for relatedness (i.e. feeling belongingness), and the need for competence (i.e. being effective, having a sense of mastery of the environment) (Deci \& Ryan, 2000; Ryan \& Deci, 2019, in press). SDT posits that particular aspects of the work environment (i.e. in the present study perceived organizational purpose) can support the satisfaction of these basic psychological needs and can foster autonomous extrinsic motivation (Ryan \& Deci, 2019, in press). Autonomous forms of motivation can, in turn, foster work engagement (Ryan \& Deci, 2019, in press; Van den Broeck, Lens, Witte, \& Van Coillie, 2013). In contrast to intrinsic motivation, autonomous extrinsic motivation concerns autonomously (i.e. volitional) enacted behaviour for extrinsic reasons (i.e. perceived organizational purpose) rather than for the inherent satisfactions associated with the enacted behaviour (Ryan \& Deci, 2019 , in press). Autonomous extrinsic motivation recognizes identified regulation 
(i.e. identification of significance and value which leads to the experience of a high degree of volition or willingness to act) and integrated regulation (i.e. the integration of identified regulation and congruence or fit with the individual's values and interests). In identified regulation the individual recognizes the significance and value of perceived organizational purpose as it contributes to society and the organization's stakeholders. In integrated regulation the individual not only recognizes and identifies with the significance and value of perceived organizational purpose but also perceives a fit between perceived organizational purpose and the individual's values.

We propose that perceived organizational purpose can support the satisfaction of employees' basic psychological needs, fosters their autonomous extrinsic motivation through identified regulation and, therefore, can influence work engagement directly (Ryan \& Deci, 2019, in press; Van den Broeck et al., 2013). First, we argue that perceived organizational purpose supports the satisfaction of autonomy in that it is perceived by employees to be aspirational, inspirational, and significant in contributing to society and thereby promotes an employee's willingness to put effort in the job volitionally (Collins \& Porras, 2008; Hurth et al., 2018). Second, employees may perceive the organization's purpose as an understanding of contributing to the larger whole by working together with colleagues in a team and other departments, thereby living the organization's purpose. Thus, by contributing to society, they may experience a sense of belonging to the organization that goes beyond the self and the job. Hence, perceived organizational purpose supports the satisfaction of relatedness (Hollensbe et al., 2014; Moynihan \& Pandey, 2007). Third, employees may perceive organizational purpose as an experience of having challenging positive impact on society by doing work they are good at. The perception of the organization's purpose thus provides the employee with an understanding what he or she contributes in and beyond the job they are good at and a challenge for development and growth, hence perceived organizational purpose supports the satisfaction of competence.

In the light of the account above, perceived organizational purpose can contribute to satisfying employees' basic psychological needs of autonomy, relatedness, and competence. Doing so, it can foster identified regulation which is the individual values and identifies with the significance of perceived organizational purpose. Thus, by supporting the basic psychological needs, perceived organizational purpose promotes autonomous extrinsic motivation that influences work engagement directly (Ryan \& Deci, 2019, in press; Van den Broeck et al., 2013). Therefore, our first hypothesis is:

H1: Perceived organizational purpose is positively related to work engagement. 


\section{The Mediating Role of Person-Organizational Purpose (P-OP) Fit in the Relationship between Perceived Organizational Purpose and Work Engagement}

We propose that perceived organizational purpose can promote the most autonomous form of extrinsic motivation, which is integrated regulation, through P-OP fit (Ryan \& Deci, 2019, in press). P-OP fit can be regarded as a type of person-organization value congruence (Cable \& DeRue, 2002; Kristoff, 1996) and is defined as the value-congruence between core personal values and the perceived core organizational values related to organizational purpose. When the organizational purpose is signalled, the importance of the core organizational values related to organizational purpose are thus reflected. We define core organizational values as "a unique set of organizational wide beliefs and ideas that intrinsically influence the attitudes and behaviours of employees to achieve institutional and greater societal goals as well as promote employee attainment of personal aspirations" (Ferguson \& Milliman, 2008, p. 441). Perceived P-OP fit refers to the belief that the perceived core organization's values reflected by organizational purpose are similar to or supportive of those core values of the individual (Chatman, 1989; Kristof, 1996). $\mathrm{P}-\mathrm{OP}$ fit differs from $\mathrm{P}-\mathrm{O}$ value congruence in the sense that P-OP fit refers to the congruence of personal values and core organizational values related to the organization's purpose and not to other organizational values. For example, let us assume that the founder of an organization built the organization's purpose around the core organizational value trust. If an employee values trust, this will likely lead to a good fit with the organization's core organizational value (trust), thus a good P-OP fit. Alternatively, if an individual does not value trust, this results in a poor fit with the organization's value, hence a poor P-OP fit. Thus, if one accepts the premise that organizational purpose is value based and reflects the importance of core organizational values, then perceived organizational purpose is likely to be positively related to P-OP fit. Thus, perceived organizational purpose tends not only to reflect the importance of core organizational values but also supports and reinforces personal values to ensure a good fit between employee values and core organizational values (Dimiziani, 2019; Downes, Kristof-Brown, Judge, \& Darnold, 2017; Ellsworth, 2002). This leads to the following hypothesis:

\section{H2: Perceived organizational purpose is positively related to perceived P-OP fit.}

From a P-O fit perspective, the more individuals perceive fit in terms of value congruence, the more likely it is that this $\mathrm{P}-\mathrm{O}$ fit positively influences outcomes and employees' optimal functioning (Edwards \& Shipp, 2007). According to Leiter and Maslach (2003), values are at the heart of individuals' relationships with their organizations and form a motivating connection. As such, value congruence produces an indefinite energetic continuation that supports work engagement (Leiter \& Maslach, 2003). In addition, perceptions of a good fit generate a sense of belonging towards the organization, which supports the satisfaction of the basic 
psychological need relatedness and thus fosters autonomous motivation, which is a key condition for work engagement (Ryan \& Deci, 2019, in press; Van den Broeck et al., 2013). Hence, a good P-O fit tends to foster employees' work engagement as previous research has shown (e.g. Kodden \& Van Ingen, 2019). In the present study, P-OP fit is a value-congruence type of P-O fit. This reasoning leads to the following hypothesis:

\section{H3: Perceived P-OP fit is positively related to work engagement.}

We propose that perceived organizational purpose supports the basic psychological needs, promotes autonomous extrinsic motivation, specifically integrated regulation, through P-OP fit, thereby indirectly influencing work engagement (Dimiziani, 2019; Downes et al., 2017; Ryan \& Deci, 2019, in press). Perceived organizational purpose signals to employees the importance of core organizational values, thereby positively influencing P-OP fit. In turn, P-OP fit is likely to foster higher levels of work engagement. As such, integrated regulation explains the relationship between perceived organizational purpose and work engagement in terms of congruence between the individual's values and the core organizational values, which are reflected by organizational purpose. Hence, this reasoning leads to the following hypothesis:

H4: Perceived organizational purpose indirectly affects work engagement through perceived P-OP fit, whereby perceived organizational purpose positively affects perceived P-OP fit, and perceived P-OP fit, in turn, positively affects work engagement.

The conceptual model in Figure 1 shows the direct and indirect (through P-OP fit) effects of perceived organizational purpose on work engagement.

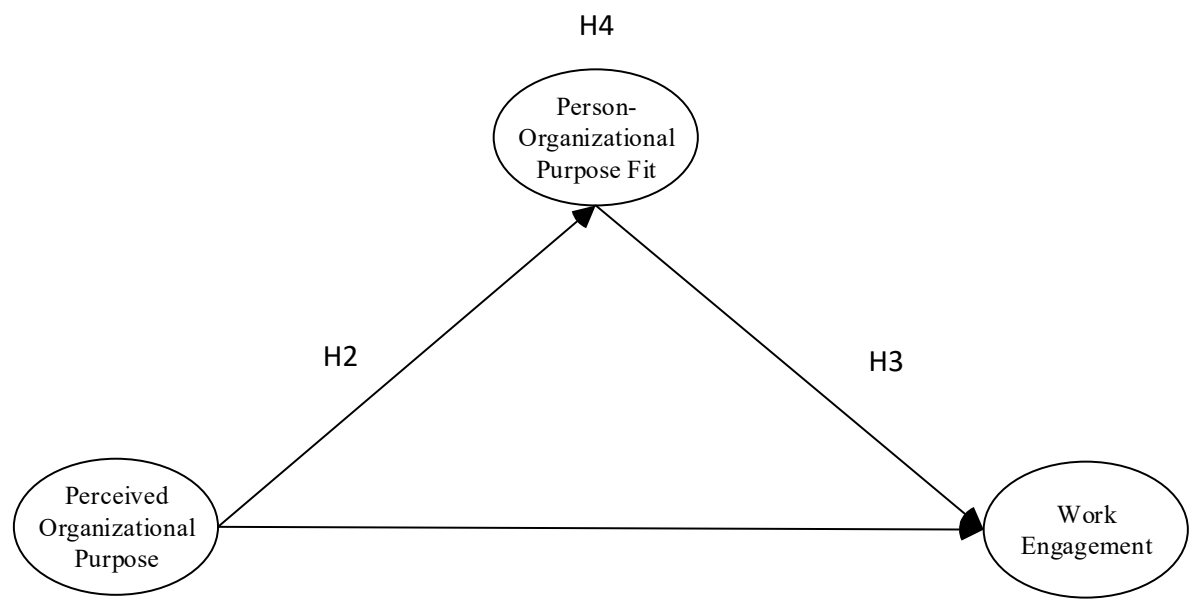

$\mathrm{H} 1$

Figure 1. Effects of perceived organizational purpose and P-OP fit on work engagement. 


\section{Methodology}

\section{Procedure and Participants}

Since the financial crisis, the financial sector has suffered diminishing levels of trust and engagement amongst employees and customers (e.g. Hartz \& Fassauer, 2013). To regain trust from society, many of the institutions in this sector re-evaluated their purpose. For example, one big bank which participated in this study reported as of 2014 its intended purpose in its annual report and still signals this purpose actively to both internal and external stakeholders. Rather than solely focusing on making profit and maximizing shareholder value, other financial institutions also issued and signalled intended purpose statements actively to internal and external stakeholders which focused, for instance, on sustainable development of society and future generations. Furthermore, these banks also signal their values to internal and external stakeholders. For example, one big bank signalled values such as honesty, prudence, and responsibility. As these institutions have openly re-considered their intended purpose and actively started signalling their purpose and the important core values, a focus on perceived organizational purpose among employees working at these organizations is particularly suitable for the present study.

Data were collected amongst 517 knowledge workers (3,877 people invited) from five financial institutions in the Dutch financial services industry. The response rate was $13.3 \%$. The data have been collected via an online questionnaire that was distributed via mail, containing an anonymous link, and by means of convenience and snowball sampling. In terms of gender, $34.6 \%(\mathrm{~N}=179)$ were female, $65.4 \%(\mathrm{~N}=$ 338) were male. With respect to the role in the organization, $17.8 \%$ were manager $(\mathrm{N}=92), 36.2 \%$ were specialist $(\mathrm{N}=187), 30.9 \%$ were consultant/advisory $(\mathrm{N}=$ $160)$ and $15.1 \%$ were belonging to a support role $(\mathrm{N}=78)$. Slightly more than half of the participants $(51.3 \%)$ had more than twenty years work experience. Hundred and twelve participants $(21.7 \%)$ indicated their tenure at their current employer was more than twenty years.

\section{Measures}

Work engagement. The English version of the validated nine-item (e.g. 'At my work, I feel that I am bursting with energy') short version of the Utrecht Work Engagement Scale (UWES) (Schaufeli, Bakker, \& Salanova, 2006) was used to assess work engagement. Employees used a 7-point rating scale ranging from 0 (never) to 6 (always). Construct reliability (CR) was.93, exceeding the threshold of.70 (Hair, Black, Babin, \& Anderson, 2010).

Perceived organizational purpose. Perceived organizational purpose was measured by requesting participants to fill in a three-item scale based on the definition of organizational purpose used in the present study (HBR, 2015). The three items are 'My organization's purpose is an aspirational reason for being', 'My organization's 
purpose is inspirational and calls to action for the organization and its partners and stakeholders', and 'My organization's purpose provides benefit to local and global society.' Respondents rated each item on a 5-point Likert scale ranging from (1) strongly disagree to (5) strongly agree. Construct reliability was found to be.79, exceeding the threshold of.70 (Hair et al., 2010).

Perceived person-organizational purpose fit. Participants reported their subjective POP fit by responding to a three-item scale adapted from Cable and DeRue (2002). The three items are 'The things that I value in life are very similar to the things that my organization values', 'My personal values match my organization's purpose, values and culture', and 'My organization's purpose provides a good fit with the things that I value in life.' Respondents rated each item on a 7-point Likert-type scale ranging from (1) strongly disagree to (7) strongly agree. Construct reliability was.93, exceeding the threshold of.70 (Hair et al., 2010).

\section{Confirmatory Factor Analysis}

To evaluate the measurement model, a confirmatory factor analysis (CFA) was performed. We evaluated the discriminant validity of the constructs by comparing the average variance extracted (AVE) of each construct to their shared variance with the other constructs in the model (Farrell, 2010; Hair et al., 2010). Results showed that the model had a good fit with the data, $\chi^{2}(87, \mathrm{n}=517)=337.866, p=.000, \chi^{2} / \mathrm{df}$ $=3.884, C F I=.954, T L I=.944, I F I=.954, S R M R=.041, R M S E A=.075$. CRs of all latent variables exceeded the.70 threshold and the AVE of all latent variables exceeded the.50 threshold (Hair et al., 2010). In Table 1, CRs, AVEs, standardized correlations, and shared variances amongst latent variables or constructs are presented, showing that construct reliability and discriminant validity of the constructs are supported. This support means that the AVE of all latent variables is greater than the shared variance (represented by the squared multiple correlations above the diagonal) between each latent variable and the other constructs in the study (Farrell, 2010; Hair et al., 2010). There is no indication of multicollinearity since correlations above the. 85 threshold do not exist (Kline, 2011).

Table 1. Construct Reliability, Average Variance Extracted, Correlation Coefficients, and Shared Variances amongst Constructs.

\begin{tabular}{lllll}
\hline & CR & 1. & 2. & 3. \\
\hline 1.ORG_PURP & .79 & $(.55)$ & .43 & .24 \\
2. FIT & .93 & $.653^{* * *}$ & $(.82)$ & .25 \\
3. WE & .93 & $.486^{* * *}$ & $.501^{* * *}$ & $(.60)$ \\
\hline
\end{tabular}

$\mathrm{N}=517$. ORG_PURP = perceived organizational purpose, $\mathrm{FIT}=$ person-organizational purpose fit, $\mathrm{WE}$ $=$ work engagement. $\mathrm{CR}=$ Construct Reliability. The Average Variance

Extracted (AVE) is displayed diagonally in parentheses. The values below the diagonal 
are standardized correlation coefficients among the latent variables. The values above the diagonal are squared standardized correlation coefficients. (i.e. shared variance among latent constructs). ${ }^{*} p<.05,{ }^{* *} p<.01,{ }^{* * *} p<.001$

\section{Common Method Variance}

To ensure minimal effects of common method bias, several procedural and statistical steps were taken as recommended by Podsakoff, Mackenzie, Lee, and Podsakoff (2003) and Conway and Lance (2010). First, participants were affirmed of total confidentiality and anonymity and stimulated to respond to the questions as frankly and intuitively as possible. This was done to help lessen any evaluation comprehension and make them less likely to give socially desirable answers (Podsakoff et al., 2003).

Second, different types of rating scales were used (e.g. perceived organizational purpose had a 5-point scale ranging from 1 to 5, P-OP fit had a 7-point scale ranging from 1 to 7 , and work engagement had a 7-point scale ranging from 0 to 6). This procedure was used to help reduce potential effects of response bias (Podsakoff et al., 2003).

Third, concerns about common method variance (CMV) can be attended to by determining construct validity of the measurement scales (Conway \& Lance, 2010). Table 1 shows construct validity and the AVE of all constructs are greater than the shared variance. Demonstrating construct validity of the measures used rules out substantial methods effect (Conway \& Lance, 2010).

Fourth, by applying Harman's single factor test, the effects of CMV were also investigated. The performed CFA contained all items loading on a single factor, this 1 -factor model had poor fit with the data. Results showed that our three-factor model had the best fit compared to the one-factor Harman model indicating that CMV was not a problem (Podsakoff et al., 2003), $\chi^{2}(90, \mathrm{n}=517)=1783.332, p$ $=.000, \chi^{2} / \mathrm{df}=19.815, C F I=.688, T L I=.636, I F I=.689$, RMSEA $=.191$.

Fifth and finally, we used the unmeasured latent method construct (ULMC) approach as recommended by Podsakoff et al. (2003) to detect CMV. In this approach, the ULMC only loads on all items of the latent variables (Podsakoff et al., 2003). Adding the ULMC enhanced the fit of the model (see Table 2). This enhancement can be explained by the fact that this model has more parameters and fewer degrees of freedom ( $\mathrm{Ng} \&$ Feldman, 2013). According to Brammer, He, and Mellahi (2015), CMV can be excluded when the items of corresponding variables load higher than.50 and the loadings on the ULMC either should be smaller than those on the latent variables or non-significant. 
Table 2. CFA: Three-factor CFA Model Compared to ULMC Model

\begin{tabular}{|c|c|c|c|c|}
\hline & $\chi^{2}$ & df & p & $\chi 2 / d f$ \\
\hline $\begin{array}{l}\text { Three-factor } \\
\text { CFA model }\end{array}$ & 441.457 & 129 & .000 & 3.422 \\
\hline $\begin{array}{l}\text { ULMC model } \\
\text { (four-factor) }\end{array}$ & 232.190 & 72 & .000 & 3.225 \\
\hline \multicolumn{5}{|c|}{ ULMC Model Factor Loading: standardized factor loadings } \\
\hline Item & $\begin{array}{l}\text { Organiza- } \\
\text { tional Pur- } \\
\text { pose }\end{array}$ & $\begin{array}{l}\text { Work En- } \\
\text { gagement }\end{array}$ & P-OP FIT & $\begin{array}{l}\text { ULMC } \\
\text { vari- } \\
\text { able }\end{array}$ \\
\hline PURP1 & $0.77^{* * *}$ & & & 0.08 \\
\hline PURP2 & $0.78^{* * *}$ & & & 0.22 \\
\hline PURP3 & $0.67^{* * *}$ & & & 0.03 \\
\hline ABS3 & & $0.47^{* * *}$ & & $0.63^{* * *}$ \\
\hline ABS2 & & $0.66^{* * *}$ & & 0.36 \\
\hline ABS1 & & $0.70^{* * *}$ & & 0.20 \\
\hline DED3 & & $0.80^{* * *}$ & & 0.13 \\
\hline DED2 & & $0.89^{* * *}$ & & 0.10 \\
\hline DED1 & & $0.86^{* * *}$ & & 0.02 \\
\hline VIG3 & & $0.79^{* * *}$ & & 0.01 \\
\hline VIG2 & & $0.82^{* * *}$ & & 0.05 \\
\hline VIG1 & & $0.81^{* * *}$ & & 0.03 \\
\hline FIT1 & & & $0.86^{* * *}$ & 0.15 \\
\hline FIT2 & & & $0.91^{* * *}$ & 0.14 \\
\hline FIT3 & & & $0.90^{* * *}$ & 0.21 \\
\hline
\end{tabular}

${ }^{* * *} p<.001$

Table 2 shows that the standardized factor loadings of our constructs are all significant and all above.50 except for ABS3 (.47). All standardized factor loadings of the ULMC are considerably below the threshold of.50 (Hair et al., 2010). Again, the exception is the standardized factor loading ABS3 on the ULMC (.63). Moreover, only one factor loading of the ULMC is significant (ABS3) and 14 are non-significant. This suggests CMV to be present. The threshold of.50 (Hair et al., 2010) was not exceeded regarding the AVE of the ULMC (AVE =.0490) and $4.90 \%$ of the variance was accounted for by CMV. Concern about inflated relationships would come up if CMV would reach a percentage of $70 \%$ (Fuller, Simmering, Atinc, Atinc, \& Babin, 2016). From the ULMC approach, it can be concluded that CMV is present, however it does not pose a serious threat to the data in the present study (Conway \& Lance, 2010; Podsakoff et al., 2003). 


\section{Data Analysis Strategy}

The hypotheses were tested by conducting structural equation modelling (SEM) analyses in AMOS 25. First, the hypothesized mediation model was examined. For this model, we examined the significance of the relationship between predictor and mediator (a-path), the relationship between mediator and outcome (b-path) and the indirect effect (ab-path). Since the sample size was large enough, we used the Monte Carlo method (Biesanz, Falk, \& Savalei, 2010) to test the significance of the indirect effect. The $95 \%$ credible intervals were calculated using the software created by Biesanz et al. (2010). The unstandardized coefficients were used to compute the indirect effects. Moreover, we investigated whether there were direct, indirect, and total effects by measuring the differences between the model without a direct effect and the hypothesized indirect effects model.

\section{Results}

Our results show that the hypothesized indirect effects model had a good fit with the data, $\chi^{2}(101, \mathrm{n}=517)=361.415, p=.000, \chi^{2} / \mathrm{df}=3.578, C F I=.954, T L I$ $=.945, I F I=.954, S R M R=.043, R M S E A=.071$. The results of the SEM analyses are depicted in Figure 1. Perceived organizational purpose is significantly related to P-OP fit $(Y=.65, p<.001)$ and work engagement $(Y=.28, p<.001)$ and P-OP fit is significantly related to work engagement $(\Upsilon=.32, p<.001)$. Hence, support was found for hypotheses one, two, and three. Support was also found for hypothesis four, namely that P-OP fit had an indirect effect on the relationship between perceived organizational purpose and work engagement (indirect effect $=.286$, LLCI $=.177$, ULCI $=.405$ ). 


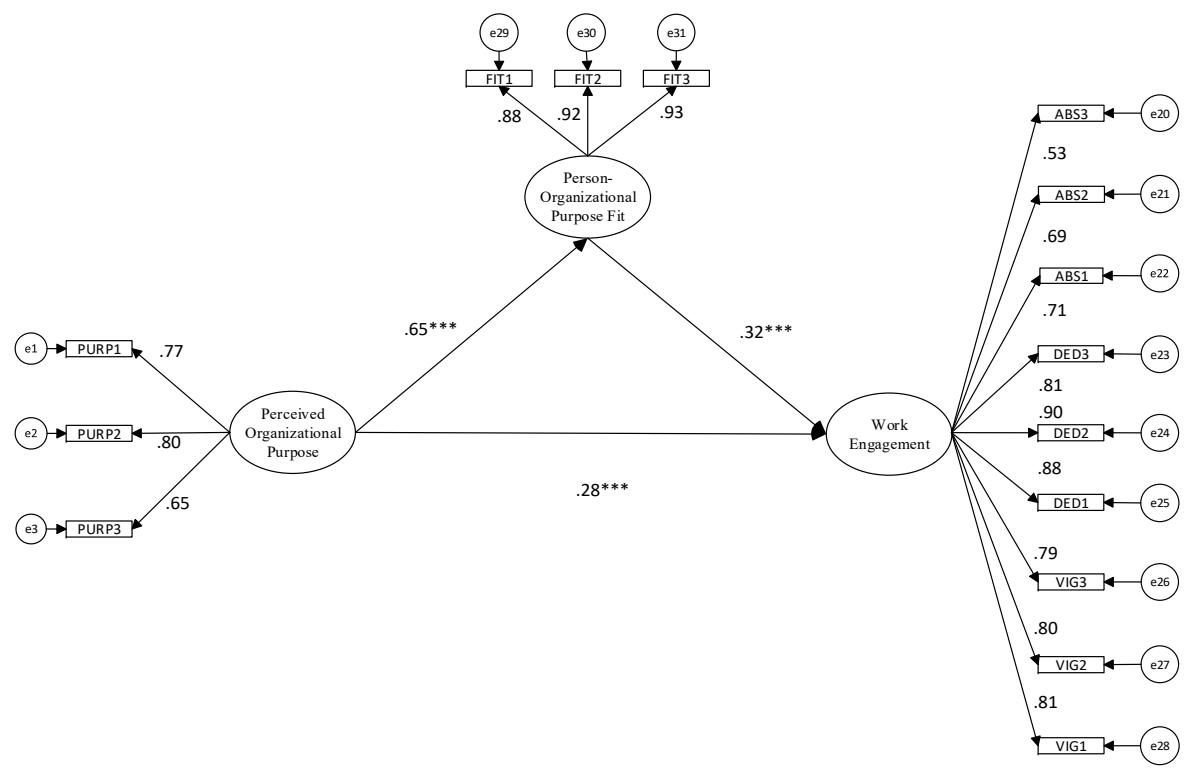

Figure 2. Standardized estimates for the proposed partial mediation model; $p<.001$. Error terms of the endogenous variables have been omitted for presentation purposes.

Next, we compared the hypothesized indirect effect model to the model without the direct effect. Results showed that this model also had a good fit with the data, $\chi^{2}(102, \mathrm{n}=517)=376.221, p=.000, \chi^{2} / \mathrm{df}=3.688, C F I=.952, T L I=.943$, IFI $=.952, S R M R=.0583, R M S E A=.072$. Based on a chi-square difference test, however, it showed that the inclusion of the direct path from perceived organizational purpose to engagement in the mediation model significantly enhanced the fit of the model in relation to the model without the direct effect, $\Delta \chi 2(1)=14.806, p<.05$. After examining these models, we concluded that our hypothesized model had the best fit to the data (see Table 3).

Table 3. SEM: Comparison of Hypothesized Partial and Full Mediation Model

\begin{tabular}{lccccccl}
\hline & $\chi 2$ & df & $\chi 2 / d f$ & CFI & IFI & SRMR & $\begin{array}{l}\text { Model Compar- } \\
\text { ison }\end{array}$ \\
\hline $\begin{array}{l}\text { Hypothesized } \\
\text { model }\end{array}$ & 361.415 & 101 & 3.578 & .954 & .954 & .0430 & $\begin{array}{l}\Delta \chi 2(1)=14.806, \\
\text { sig. } p<.05\end{array}$ \\
$\begin{array}{l}\text { Full mediation } \\
\text { model }\end{array}$ & 376.221 & 102 & 3.688 & .952 & .952 & .0583 & \\
\hline
\end{tabular}

IFI: Incremental Fit Index, CFI: Comparative Fit Index, SRMR: standardized root mean square residual. 


\section{Discussion}

Building on SDT and P-O-fit theory, the present study aimed to contribute to the literature on organizational purpose by examining the relationship between perceived organizational purpose and work engagement and the mediating role of person-organizational purpose (P-OP) fit herein. More specifically, we gained insight into two mechanisms explaining the relationship between perceived organizational purpose and work engagement at the individual level.

First, in line with our expectations, we found that perceived organizational purpose was positively related to work engagement. In line with SDT (cf. Ryan \& Deci, 2019, in press), this finding suggests that perceived organizational purpose has motivational potential to foster work engagement directly through contributing to the satisfaction of employees' basic psychological needs - autonomy, relatedness, and competence - and promoting their autonomous extrinsic motivation. Employees willingly and volitionally have chosen to work for an organization as they identify with its purpose and values. This fosters employees' autonomy to fulfil the organization's purpose through work. Furthermore, the organization's purpose unifies employees working towards a shared vision through a concrete mission and corresponding goals, thus fostering the perception of belonging to something larger than themselves. Moreover, having a clear and challenging purpose to strive for, employees will not only express their competence through work, but it is likely they will also seek to develop and grow their competence.

In striving for purpose as offered by an organization, individuals may also experience a sense of meaningfulness and significance in their work as they perceive their work as part of the larger organization, which contributes to the well-being of the society the organization is part of, and its constituents. As employees can be seen as a constituent of society that the organization benefits, organizational purpose is likely to improve employees' well-being through the satisfaction of their basic psychological needs (e.g. Ryan \& Deci, 2019, in press). As employees pursue strivings they find satisfying or significant (i.e. organizational purpose), they may also create conditions for enhancing not only their own well-being but also the well-being of others, whether inside or outside their organization. As such, this study concerns a unifying factor, organizational purpose, which can foster both individual employee well-being and, through organizational activities, collective societal well-being. Considering the importance of the satisfaction of basic psychological needs, comprehending and improving the conditions under which employees' needs can be supported, is an important concern for organizations and the societies they play a role in.

Second, also in line with our expectations, perceived P-OP fit mediated the relationship between perceived organizational purpose and work engagement. This finding reveals that by reflecting the importance of the organization's core values, perceived organizational purpose positively influences employees' P-OP fit percep- 
tion, which in turn fosters work engagement. This finding supports perceived organizational purpose to be an antecedent of the value congruence type of P-O fit (Dimiziani, 2019; Downes et al., 2017; Kristoff, 1996).

\section{Conclusion}

\section{Theoretical implications}

The present study provides three distinctive implications for the literature on organizational purpose.

The first implication concerns demonstrating the relationship between perceived organizational purpose and work engagement. Perceived organizational purpose supports the satisfaction of basic psychological needs of autonomy, relatedness, and competence and promotes autonomous extrinsic motivation of identified regulation (Deci \& Ryan, 2000; Ryan \& Deci, 2019, in press). Thus, we contribute to literature on organizational purpose in a way that organizational purpose, as a particular aspect of the work environment, is capable of fostering employees' motivation, thereby relating organizational purpose to work motivation literature, specifically SDT literature (Deci \& Ryan, 2000; Ryan \& Deci, 2019, in press).

Second, perceived organizational purpose directly influences work engagement. This implies that we add to the literature on organizational purpose as it can be considered an important antecedent of work engagement (Schaufeli et al., 2002).

The third and final implication for organizational purpose literature lies in our proposition that perceived organizational purpose can function as an antecedent of P-O fit (Kristoff, 1996). By reflecting the importance of core organizational values related to organizational purpose, perceived organizational purpose thereby supports and reinforces personal values, which in turn enhance P-O fit perceptions. Furthermore, this study supports the theory that suggests $\mathrm{P}-\mathrm{O}$ fit as value congruence can be considered a valuable mediator in the relationship between perceptions of work context and work outcomes (e.g. Downes et al., 2017). In the present study, perceived organizational purpose influences work engagement indirectly through P-OP fit (i.e. integrated regulation) (Ryan \& Deci, 2019, in press), thereby also adding to literature on SDT in relation to P-O fit (e.g. Downes et al., 2017).

\section{Practical implications}

The results of the present study have several practical implications. Given the two mechanisms revealed in the present study that explain the relationship between perceived organizational purpose and work engagement at the individual level, organizations might consider effectuating a clear, concise, and understandable purpose, evaluating and living their purpose to foster stakeholder action and engagement. Specifically for employees, organizations thereby provide them with insight in what 
their individual jobs contribute to the larger whole. The present results showed that organizational purpose can serve as a motivational construct. Thus, it is likely that perceived organizational purpose not only affects individuals' work engagement positively but may also affect other employee outcomes such as performance (Ryan $\&$ Deci, 2019, in press) and organizational outcomes such as organizational performance (Bakker et al., 2014). From a P-O fit perspective, perceived organizational purpose is likely to affect P-OP fit, and this will, in turn, likely result in higher levels of other work outcomes such as commitment and job satisfaction (e.g. Cable \& DeRue, 2002).

\section{Limitations}

The present study has several limitations. First, due to the cross-sectional, non-experimental design, definite causal inferences cannot be drawn. To further investigate the causality of the hypothesized relationships, longitudinal research is needed.

Second, self-reported single-source data have been used. Since the present study focuses on individual perceptions, a self-report questionnaire was deemed appropriate. Nevertheless, due to the cross-sectional and single-source nature of our study, CMV might have affected the results of the study (Conway \& Lance, 2010; Podsakoff et al., 2003). However, our CMV analysis revealed that CMV was not likely a significant concern (Conway \& Lance, 2010; Podsakoff et al., 2003). Nevertheless, the results of this study should be interpreted with care.

Third, since the focus in this study was on the financial services sector, the results may not be generalizable to other sectors. In order to see whether the results are generalizable to other industries, future research in this field should focus on other (service) industries, possibly including multiple stakeholders such as customers and prospective employees.

Fourth and finally, in the present study, one specific mediator was considered, however, other mediators may likely also play a role in explaining the relationship between perceived organizational purpose and employee outcomes including work engagement. Taking into account other motivational theories (see Kanfer, Frese, \& Johnson, 2017) and the literature on meaningful work (e.g. Lysova et al., 2019), we believe the Job Characteristics Model (Hackman \& Oldham, 1976) might be a relevant model since purpose and meaning are related constructs (e.g. Rosso et al., 2010). Perceived organizational purpose can be assumed to foster the perception of task significance, which triggers the psychological state of perceived meaningfulness that must be present for internally motivated work behaviour and thus may act as a mediator in the relationship between perceived organizational purpose and work engagement. Thus, we see possibilities for future research to incorporate meaningful work. 
Based on the limitations presented above, we recommend conducting multi-level, multi-source, and longitudinal research on organizational purpose and its influence on stakeholders and stakeholder interdependencies. Whereas the present study showed the positive relationship between purpose and employee work engagement and the mediating role of P-OP fit, future research at the individual level may look into other mediators such as perceived meaningfulness, other multi-disciplinary perspectives such as marketing or employer branding, and research whether perceptions of organizational purpose are positively associated with attracting new talent or with customer engagement. In other words, is organizational purpose also capable of invoking psychological processes among stakeholders outside the organization?

Summarizing, the interest in understanding organizational purpose has increased amongst academics and practitioners. While organizational purpose used to refer to 'reason for being,' some academics propose to see the construct as potentially providing an overarching framework to communicate the role of business in society (Hollensbe et al., 2014) that can engage internal and external stakeholders and foster action. The results of the present study showed that organizational purpose can be perceived as more than a reason for being, it might be considered a motivational construct that has the capacity to support the satisfaction of basic psychological needs and promote autonomous extrinsic motivation, thereby increasing work engagement. As such, by engaging through purpose, organizations can deploy their purpose in employer branding as part of SHRM. The present study showed that focusing on organizational purpose can provide scholars with a valuable overarching framework for connecting different research streams and practitioners with an overarching framework for connecting different stakeholders to their organization's values and goals, leading to benefits for all parties.

\section{References}

App, S., Merk, J., \& Büttgen, M. (2012). Employer branding: Sustainable HRM as a competitive advantage in the market for high-quality employees. Management Revue, 23(3), 262-278. https://doi.org/ 10.1688/1861-9908_mrev_2012_03_App

Bakker, A. B., Demerouti, E., \& Sanz-Vergel, A. I. (2014). Burnout and work engagement: The JD-R approach. Annual Review of Organizational Psychology and Organizational Behavior, 1(1), 389-411. https://doi.org/10.1146/annurev-orgpsych-031413-091235

Biesanz, J., Falk, C., \& Savalei, V. (2010). Assessing mediational models: Testing and interval estimation for indirect effects. Multivariate Behavioral Research, 45(4), 661-701. https://doi.org /10.1080/00273171.2010.498292

Brammer, S., He, H., \& Mellahi, K. (2015). Corporate social responsibility, employee organizational identification, and creative effort. The moderating impact of corporate ability. Group \& Organization Management, 40(3), 323-352. https://doi.org/10.1177/1059601114562246 
Cable, D., \& DeRue, D. (2002). The convergent and discriminant validity of subjective fit perceptions. Journal of Applied Psychology, 87(5), 875-884. https://doi.org/10.1037/0021-9010 .87 .5 .875

Chatman, J. A. (1989). Improving interactional organizational research: A model of person-organization fit. Academy of Management Review, 14(3), 333-349. https://doi.org/10.5465/amr.198 9.4279063

Collins, J. C., \& Porras, J. I. (2008). CMR classics: organizational vision and visionary organizations. California Management Review, 50(2), 117-137. https://doi.org/10.2307/41166438

Conway, J., \& Lance, C. (2010). What reviewers should expect from authors regarding common method bias in organizational research. Journal of Business and Psychology, 25(3), 325-334. https://doi.org/10.1007/s10869-010-9181-6

Deci, E. L., \& Ryan, R. M. (2000). The what' and'why' of goal pursuits: Human needs and the self-determination of behavior. Psychological Inquiry, 11(4), 319-338. https://doi.org/10.1207/ S15327965PLI1104_01

Dimiziani, A. (2019). Putting Values into Action: Delivering on purpose by establishing, embedding, enacting, and expressing your values. In M.S. Montgomery (Ed.), Perspectives on Purpose: Building Brands and Businesses for the Twenty-First Century (pp. 89-102). New York, NY: Routledge.

Downes, P. E., Kristof-Brown, A. L., Judge, T. A., \& Darnold, T. C. (2017). Motivational mechanisms of self-concordance theory: Goal-specific efficacy and person-organization fit. Journal of Business and Psychology, 32(2), 197-215. https://doi.org/10.1007/s10869-016-944 $4-y$

Edwards, J.R., \& Shipp, A.J. (2007). The Relationship Between Person-Environment Fit and Outcomes: An Integrative Theoretical Framework. In C. Ostroff \& T. A. Judge (Eds.), Perspectives on organizational fit (pp. 209-258). San Francisco, Jossey-Bass.

Ehnert, I. (2014). Paradox as a Lens for Theorizing Sustainable HRM: Mapping and Coping with Paradoxes and Tensions. In Sustainability and Human Resource Management, 247-271. Heidelberg, Berlin: Springer-Verlag.

Ellsworth, R. R. 2002. Leading with purpose: The new corporate realities. Stanford, California: Stanford University Press.

Farrell, A. (2010). Insufficient discriminant validity: comment on Bove, Pervan, Beatty, and Shiu (2009). Journal of Business Research, 63(3), 324-327. https://doi.org/10.1016/j.jbusres.2009.05 .003

Ferguson, J., \& Milliman, J. (2008). Creating effective core organizational values: A spiritual leadership approach. International Journal of Public Administration, 31(4), 439-459. https://doi .org/10.1080/01900690701590835

Fuller, C. M., Simmering, M. J., Atinc, G., Atinc, Y., \& Babin, B. J. (2016). Common methods variance detection in business research. Journal of Business Research, 69(8), 3192-3198. https:// doi.org/10.1016/j.jbusres.2015.12.008

Hackman, J.R., \& Oldham, G.R. (1976). Motivation through the design of work: Test of a theory. Organizational Behavior and Human Performance, 16(2)), 250-279.

Hair, J., Black, W., Babin, B., \& Anderson, R. (2010). Multivariate data analysis: A global perspective. Upper Saddle River, NJ, Pearson/Prentice Hall. 
Hartz, R., \& Fassauer, G. (2013). Performance Principle and Organizational Compensation Practice in the Context of the Global Financial Crisis: A Discourse-analytical Study. Management Revue, 24(1), 30-52. https://doi.org/ 10.1688/1861-9908_mrev_2013_01_Hartz

Harvard Business Review, analytic services report. (2015). The Business Case for Purpose. Boston, Massachusettes: Harvard Business School Publishing.

Hollensbe, E., Wookey, C., Loughlin, H., George, G., \& Nichols, V. (2014). Organizations with purpose. Academy of Management Journal, 57(5), 1227-1234. https://doi.org/10.5465/amj.201 4.4005

Hurth, V., Ebert, C., \& Prabhu, J. (2018). Organisational purpose: the construct and its antecedents and consequences. Working Papers 201802, Cambridge Judge Business School, University of Cambridge.

Kanfer, R., Frese, M., \& Johnson, R. E. (2017). Motivation related to work: A century of progress. Journal of Applied Psychology, 102(3), 338. https://doi.org/10.1037/apl0000133

Kline, R. B. (2011). Principles and practice of structural equation modeling (3rd ed.). New York: Guilford Press.

Kodden, B., \& Van Ingen, R. (2019). Knowledge Productivity in the 2020s: Time for a New E/RA: A Research Study on the Impact of Organizational Design and Employee Engagement on the Knowledge Productivity of Service Firms. Journal of Applied Business and Economics, 21(4), 71-84. https://doi.org/10.33423/jabe.v21i4.2132

Kristof, A. (1996). Person-Organization Fit: an integrative review of its conceptualizations, measurement, and implications. Personnel Psychology, 49(1), 1-49. https://doi.org/10.1111/j.17446570.1996.tb01790.x

Leiter, M. P., \& Maslach, C. (2003). Areas of worklife: A structured approach to organizational predictors of job burnout. Research in Occupational Stress and Well Being, 3(1), 91-134. https:// doi.org/10.1016/S1479-3555(03)03003-8

Lips-Wiersma, M. (2002). The influence of spiritual "meaning-making" on career behavior. Journal of Management Development, 21(7), 497-520. https://doi.org/10.1108/026217102104 34638

Lysova, E. I., Allan, B. A., Dik, B. J., Duffy, R. D., \& Steger, M. F. (2019). Fostering meaningful work in organizations: A multi-level review and integration. Journal of Vocational Behavior, 110, 374-389. https://doi.org/10.1016/j.jvb.2018.07.004

Montgomery, M.S. (Ed.) (2019). Perspectives on Purpose: Building Brands and Businesses for the Twenty-First Century. New York, NY: Routledge.

Moynihan, D. P., \& Pandey, S. K. (2007). Finding workable levers over work motivation: Comparing job satisfaction, job involvement, and organizational commitment. Administration \& Society, 39(7), 803-832. https://doi.org/10.1177/0095399707305546

Ng, T., \& Feldman, D. (2013). Age and innovation-related behavior: The joint moderating effects of supervising undermining and proactive personality. Journal of Organizational Behavior, 34(5), 583-606. https://doi.org/10.1002/job.1802

Nishii, L. H. \& Wright, P. M. (2007). Variability within organizations: Implications for strategic human management (CAHRS Working Paper \#07-02). Ithaca, NY: Cornell University, School of Industrial and Labor Relations, Center for Advanced Human Resource Studies. http:/ /digitalcommons.ilr.cornell.edu/cahrswp/467 
Palmer, B., Quinn Griffin, M. T., Reed, P., \& Fitzpatrick, J. J. (2010). Self-transcendence and work engagement in acute care staff registered nurses. Critical Care Nursing Quarterly, 33(2), 138-147. https://doi: 10.1097/CNQ.0b013e3181d912d8

Piening, E. P., Baluch, A. M., \& Ridder, H. G. (2014). Mind the intended-implemented gap: Understanding employees' perceptions of HRM. Human Resource Management, 53(4), 545567. https://doi.org/10.1002/hrm.21605

Podsakoff, P., Mackenzie, S., Lee, J., \& Podsakoff, N. (2003). Common method biases in behavioral research: A critical review of the literature and recommended remedies. Journal of Applied Psychology, 88(5), 879-903. https://doi.org/ 10.1037/0021-9010.88.5.879

Rastogi, A., Pati,S. P., Krishnan, T.N., \& Krishnan, S. (2018). Causes, Contingencies, and Consequences of Disengagement at Work: An Integrative Literature Review. Human Resource Development Review, 17(1), 62-94. https://doi.org/10.1177/1534484317754160

Rosso, B.D., Dekas, K.H., \& Wrzesniewski, A. (2010). On the meaning of work: A theoretical integration and review. Research in Organizational Behavior, 30, 91-127. https://doi.org/10.101 6/j.riob.2010.09.001

Ryan, R. M., \& Deci, E. L. (2019). Brick by brick: The origins, development, and future of selfdetermination theory. In A. J. Elliot (Vol. Ed.), Advances in motivation science. 6. Advances in motivation science (pp. 111-156). Cambridge, MA: Elsevier Inc. https://doi.org/10.1016/bs.ad ms.2019.01.001

Ryan, R.M., \& Deci, E. L. (in press). Intrinsic and extrinsic motivation from a self-determination theory perspective: Definitions, theory, practices, and future directions. Contemporary Educational Psychology. https://doi.org/10.1016/j.cedpsych.2020.101860

Sanders, K., \& Yang, H. (2016). The HRM process approach: The influence of employees' attribution to explain the HRM-performance relationship. Human Resource Management, 55(2), 201-217. https://doi.org/10.1002/hrm.21661

Schaufeli, W., Bakker, A. B., \& Salanova, M. (2006). The measurement of work engagement with a short questionnaire: A cross-national study. Educational and Psychological Measurement, 66(4), 701-716. https://doi.org/10.1177/0013164405282471

Schaufeli, W., Salanova, M., Gonzalez-Roma, V., \& Bakker, A. B. (2002). The measurement of engagement and burnout: A two sample confirmatory factor analytic approach. Journal of Happiness Studies, 3(1), 71-92. https://doi.org/10.1023/A:1015630930326

Springett, N. (2005). Evaluating corporate purposes by the psychological contracts they produce. Strategic Change, 14(7), 357-366. https://doi.org/10.1002/jsc.738

Van den Broeck, A., Lens, W., De Witte, H., \& Van Coillie, H. (2013). Unraveling the importance of the quantity and the quality of workers' motivation for well-being: A person-centered perspective. Journal of Vocational Behavior, 82(1), 69-78. https://doi.org/10.1016/j.jvb.2012.1 1.005

Wang, H., Tong, L., Takeuchi, R., \& George, G. (2016). Corporate Social Responsibility: An Overview and New Research Directions. Academy of Management Journal, 59(2), 534-544. https://doi.org/10.5465/amj.2016.5001

Williams, F. (2019). The Business Case for Purpose. Friedman, Fink, and the battle for the soul of purpose. In M.S. Montgomery (Ed.), Perspectives on Purpose: Building Brands and Businesses for the Twenty-First Century (pp. 9-17). New York, NY: Routledge. 